\title{
Effects of intrauterine growth retardation on postnatal visceral and cerebral blood flow velocity
}

\author{
S T Kempley, H R Gamsu, S Vyas, K Nicolaides
}

\begin{abstract}
Blood flow velocity and pulsatility index were measured with Doppler ultrasound in the superior mesenteric artery, coeliac axis, and anterior cerebral artery in 18 very low birth weight, small for gestational age infants, and compared with findings from 18 weight matched, and 18 gestation matched, appropriate for gestational age controls. Mean velocity in the superior mesenteric artery was lower in the small for gestational age infants $(15 \mathrm{~cm} / \mathrm{s})$ than in the gestation matched control group $(20.4 \mathrm{~cm} / \mathrm{s})$. In those small for gestational age infants who had evidence of fetal hypoxia the mean velocity in the superior mesenteric artery was even lower $(11.5 \mathrm{~cm} / \mathrm{s})$. There were no differences in velocity in the cerebral artery among the groups. Infants who were small for gestational age still had significantly lower superior mesenteric artery velocity than gestation matched controls at 1 week of age.

The results suggest a specific reduction in visceral perfusion in infants who are small for gestational age and who have experienced fetal hypoxia, and this could predispose these infants to necrotising enterocolitis.
\end{abstract}

Cordocentesis has shown that fetuses that are extremely small for gestational age are chronically hypoxaemic and acidotic. ${ }^{1}$ It has also been shown by Doppler studies of the fetal circulation that in fetal hypoxaemia there is centralisation of flow with increased blood velocity and a decreased pulsatility index in the cerebral circulation, and decreased velocity with increased impedance in the aorta. ${ }^{2}$ This response maintains cerebral oxygenation while organs that are supplied by the descending aorta are likely to be deprived. In fetuses that are more severely hypoxic there is complete absence of end diastolic frequencies in the descending aorta, and after birth these infants are at increased risk of developing necrotising enterocolitis and

King's College Hospital, London,

Children Nationwide Regional Neonatal Centre ST Kempley

H R Gamsu

Department of

Obstetrics

$S$ Vyas

K Nicolaides

Correspondence to:

Dr S T Kempley,

Frederick Still W'

King's College Hospital,

London SE5 9RS.

Accepted 18 April 1991 intrauterine growth retardation (IUGR) detected before delivery. We have compared the results with those from weight matched and gestation matched control groups of babies of appropriate birth weight for gestational age. To find out if our findings are specific to the splanchnic circulation we also measured blood flow velocity in the anterior cerebral artery.

Patients and methods

Doppler studies of the superior mesenteric artery, coeliac axis, and anterior cerebral artery were made on 18 infants admitted to our unit whose birth weight was less than $1500 \mathrm{~g}$ and who were less than the 10 th centile for gestation. In all cases growth retardation was suspected antenatally, and on ultrasound examination the fetal abdominal circumference was less than the 5th centile for gestation. Antenatal Doppler studies indicating the presence or absence of end diastolic frequencies in the fetal aorta had been done as previously described. ${ }^{3}$ Because this hospital is a referral centre for antenatal diagnosis, the proportion of fetuses with absent end diastolic frequencies $(12 / 18)$ was higher than would normally be expected. For each index case a weight matched and a gestation matched control infant was selected retrospectively from a pool of 70 appropriate for gestational age infants who needed intensive care and who also had Doppler measurements made. The matched cases were the infants with the closest weight or gestation to the index case, who also had Doppler data for the same days of age. For the three infants who were small for gestational age from multiple pregnancies, the appropriately grown co-twin or co-quadruplet was used as a gestation matched control (tables 1 and 2).

Measurements were made for each infant on days 1,3 , and 7 , after delivery. Data were only included in the analysis if a measurement was available on the same day in both the index and control cases.

Blood flow velocity waveforms were obtained from each artery using a duplex ultrasound imaging and Doppler system (Hewlett Packard Sonos 100 with $7.5 \mathrm{MHz}$ imaging and $5.0 \mathrm{MHz}$ Doppler transducer). The artery was visualised using real time ultrasound, and the signals from a known segment of the artery were sampled by range gating. We corrected for the angle of insonation of the artery and eliminated artefact arising from movement of the vessel wall with a $100 \mathrm{~Hz}$ filter. The time averaged mean of the peak velocity envelope was calculated from four consecutive cardiac cycles by hand planimetry. The pulsatility index of the waveform was calculated with a Doptek 9000 spectrum analyser from signals recorded on videotape. (The pulsatility index is equal to the difference between 


\begin{tabular}{|c|c|c|c|}
\hline & \multirow{2}{*}{$\begin{array}{l}\text { Small for } \\
\text { gestational } \\
\text { age infants } \\
(n=18)\end{array}$} & \multicolumn{2}{|l|}{ Control infants } \\
\hline & & $\begin{array}{l}\text { Weight } \\
\text { matched } \\
(n=18)\end{array}$ & $\begin{array}{l}\text { Gestation } \\
\text { matched } \\
(n=18)\end{array}$ \\
\hline $\begin{array}{l}\text { Mean (range) birth weight (g) } \\
\text { Mean (range) gestation (weeks) } \\
\text { No of survivors }\end{array}$ & $\begin{array}{l}845(434-1380) \\
30 \cdot 5(25-34) \\
12\end{array}$ & $\begin{array}{l}849(506-1404) \\
25 \cdot 6(23-28) \\
14\end{array}$ & $\begin{array}{l}1565(882-2482) \\
30 \cdot 5(26-34) \\
17\end{array}$ \\
\hline
\end{tabular}

Table 2 Comparability at times of measurement between small for gestational age infants and their control groups. Figures are expressed as number of infants except where otherwise stated

\begin{tabular}{|c|c|c|c|}
\hline & \multirow{2}{*}{$\begin{array}{l}\text { Small for } \\
\text { gestational } \\
\text { age } \\
(n=18)\end{array}$} & \multicolumn{2}{|l|}{ Control infants } \\
\hline & & $\begin{array}{l}\text { Weight } \\
\text { matched } \\
(n=18)\end{array}$ & $\begin{array}{l}\text { Gestation } \\
\text { matched } \\
(n=18)\end{array}$ \\
\hline $\begin{array}{l}\text { Day } 1(\mathrm{n}=18)^{*} \\
\text { Mean (range) arterial oxygen tension }(\mathrm{kPa}) \\
\text { Mean (range) arterial blood pressure }(\mathrm{mmHg}) \\
\text { No receiving artificial ventilation } \\
\text { No with umbilical arterial catheter }\end{array}$ & $\begin{array}{l}8 \cdot 6(5 \cdot 3-13 \cdot 3) \\
35 \cdot 9(24-53) \\
12 \\
11\end{array}$ & $\begin{array}{l}9 \cdot 0(4 \cdot 4-11 \cdot 6) \\
34 \cdot 6(22-52) \\
18 \\
17\end{array}$ & $\begin{array}{l}8 \cdot 8(4 \cdot 4-15 \cdot 2) \\
37 \cdot 3(30-58) \\
15 \\
15\end{array}$ \\
\hline $\begin{array}{l}\text { Day } 3(n=10) \\
\text { No receiving artificial ventilation } \\
\text { No with umbilical arterial catheter } \\
\text { No receiving enteral feeds }\end{array}$ & $\begin{array}{l}5 \\
4 \\
1\end{array}$ & $\begin{array}{r}8 \\
10 \\
0\end{array}$ & $\begin{array}{l}5 \\
5 \\
3\end{array}$ \\
\hline $\begin{array}{l}\text { Day } 7(n=8) \\
\text { No receiving artificial ventilation } \\
\text { No with umbilical arterial catheter } \\
\text { No receiving enteral feeds }\end{array}$ & $\begin{array}{l}1 \\
3 \\
4\end{array}$ & $\begin{array}{l}5 \\
5 \\
2\end{array}$ & $\begin{array}{l}1 \\
1 \\
4\end{array}$ \\
\hline
\end{tabular}

*No baby was given enteral feeds on day 1 .

systolic and diastolic velocities divided by the mean velocity.)

The significance of the differences in the results from small for gestational age infants and their control groups was assessed by Student's unpaired $t$ test. Infants with absent fetal aortic end diastolic frequencies were analysed as a subgroup.

\section{Results}

MEASUREMENTS ON THE FIRST DAY

Mean velocity in the superior mesenteric artery was significantly lower in the infants who were small for gestational age $(15 \cdot 0 \mathrm{~cm} / \mathrm{s})$ than in

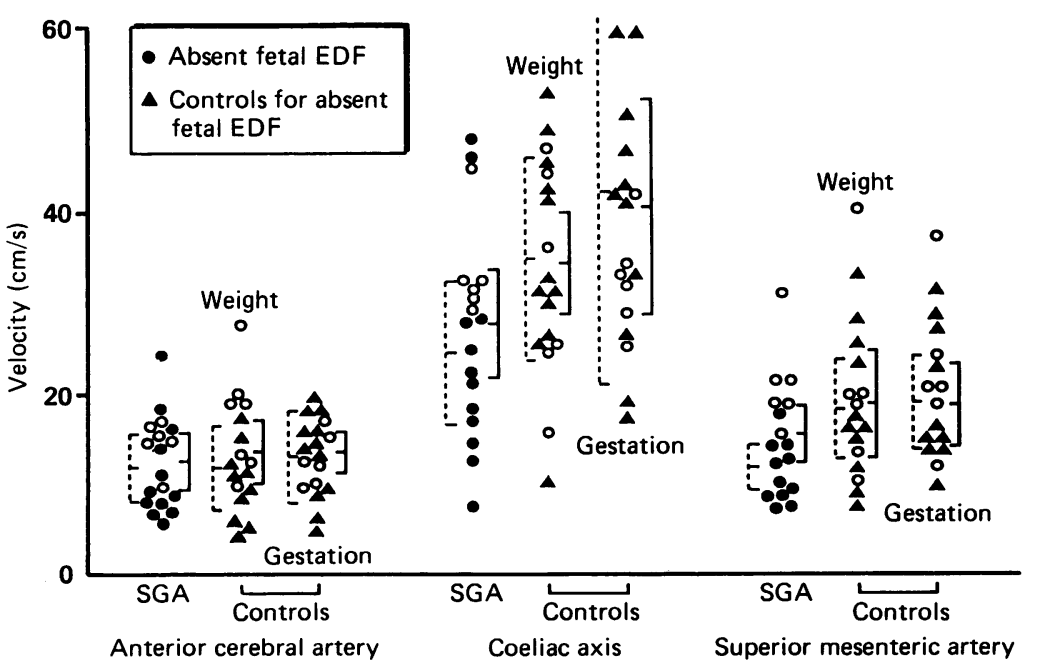

Figure 1 Blood velocity in the anterior cerebral artery, coeliac axis, and superior mesenteric artery during the first day of life in small for gestational age (SGA) infants and their weight matched and gestation matched controls. Means and $95 \%$ confidence intervals are shown to the right of each group as solid lines. Small for gestational age infants with absent fetal aortic end diastolic frequencies $(E D F)$ are shown as are their controls. Means and $95 \%$ confidence intervals are shown to the left of these subgroups by broken lines. their gestation matched controls $(20.4 \mathrm{~cm} / \mathrm{s}$, $\mathrm{p}<0.05$; fig 1). This was also the case for the mean velocity in the coeliac axis (small for gestational age: $27 \cdot 0 \mathrm{~cm} / \mathrm{s}$; controls: $40 \cdot 8 \mathrm{~cm} / \mathrm{s}$; $\mathrm{p}<0.05)$. In contrast there was no significant difference between the groups in mean velocity in the anterior cerebral artery.

When the small for gestational age infants with absent end diastolic frequencies in utero were analysed separately the results were more striking. Mean velocity in the superior mesenteric artery was significantly lower in the small for gestational age infants $(11.5 \mathrm{~cm} / \mathrm{s})$ than in their weight or gestation matched control groups (weight matched: $18.6 \mathrm{~cm} / \mathrm{s}, \mathrm{p}<0.05$; gestation matched: $19 \cdot 1 \mathrm{~cm} / \mathrm{s}, \mathrm{p}<0.05)$. The same was also true for the mean velocity in the coeliac axis (small for gestational age: $23.9 \mathrm{~cm} / \mathrm{s}$; weight matched: $34.9 \mathrm{~cm} / \mathrm{s}, \mathrm{p}<0.05$; gestation matched: $44.9 \mathrm{~cm} / \mathrm{s}, \mathrm{p}<0.05)$. Again, there were no significant differences between groups in the anterior cerebral artery velocities. Velocity in the superior mesenteric artery of infants who had had absent fetal end diastolic frequencies was significantly lower than in small for gestational age infants in whom end diastolic frequencies had been recorded $(11.5 \mathrm{~cm} / \mathrm{s}$ compared with $21.4 \mathrm{~cm} / \mathrm{s} ; \mathrm{p}<0.01$ ).

The pulsatility index was significantly higher in the superior mesenteric artery and coeliac axis of the infants who were small for gestational age than in their weight matched controls (fig 2; superior mesenteric artery: $p<0.05$; coeliac axis: $p<0.05$ ). For those infants who had had absent aortic end diastolic frequencies in utero, the pulsatility index was significantly higher than in weight matched (superior mesenteric artery: $p<0.05$; coeliac axis: $p<0.05$ ) or gestation matched controls (superior mesenteric artery: $p<0.05$; coeliac axis: $p<0.05$ ). 


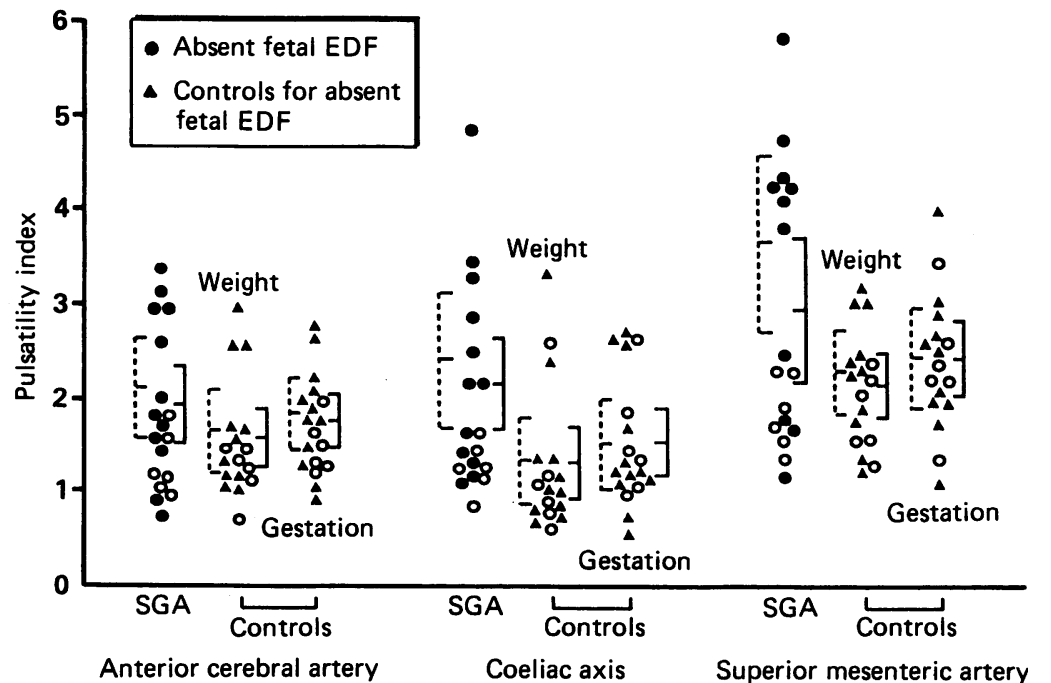

Figure 2 Pulsatility index in the anterior cerebral artery, coeliac axis, and superior mesenteric artery during the first day of life in small for gestational age (SGA) infants and their weight matched and gestation matched controls. Means and $95 \%$ confidence intervals are shown to the right of each group as solid lines. Small for gestational age infants with absent fetal aortic end diastolic frequencies (EDF) are shown as are their controls. Means and 95\% confidence intervals are shown to the left of these subgroups by broken lines.

MEASUREMENTS ON DAYS 3 AND 7

On day 3, mean velocity in the anterior cerebral artery was significantly higher in infants who were small for gestational age $(23.3 \mathrm{~cm} / \mathrm{s})$ than in weight matched controls $(16.4 \mathrm{~cm} / \mathrm{s}, \mathrm{p}<0.01)$. There were no other significant differences between the groups.

On day 7 the mean velocities in the superior mesenteric artery and the coeliac axis were significantly lower in infants who were small for gestational age than in their gestation matched controls (fig 3; superior mesenteric artery: 21.9 $\mathrm{cm} / \mathrm{s}$ in small for gestational age infants compared with $33.8 \mathrm{~cm} / \mathrm{s}$ in controls, $p<0.05$; coeliac axis: $31.6 \mathrm{~cm} / \mathrm{s}$ in small for gestational age infants compared with $41.9 \mathrm{~cm} / \mathrm{s}$ in controls, $p<0.05)$. The mean percentage increase in velocity in the superior mesenteric artery from day 1 was significantly lower in the small for gestational age infants $(31 \%)$ than in the gestation matched controls $(117 \%, \mathrm{p}<0.05)$.

\section{Discussion}

In premature, small for gestational age infants mesenteric and coeliac arterial blood velocity



Figure 3 Blood velocity in the superior mesenteric artery on days 3 and 7 in small for gestational age (SGA) infants and their weight matched and gestation matched controls. was decreased compared with that found in appropriately grown but equally premature infants. These differences are principally accounted for by the group of small for gestational age infants who had absent end diastolic frequencies in the aorta during fetal life. In these infants velocity in the superior mesenteric artery and coeliac axis was lower than in infants of equivalent weight or gestation.

Although low velocity within an artery does not necessarily mean low flow (flow $=$ velocity $X$ cross sectional area of the vessel), it is unlikely that the small for gestational age infants had significantly larger mesenteric arteries. Indeed, the usual response of a vessel to chronic low velocity blood flow it that of a reduction in diameter of the vessel, which confirms our impression of reduced diameter of the umbilical vessels in many small for gestational age infants. Furthermore, we have found that the superior mesenteric arteries of small for gestational age infants are more difficult to visualise than those of appropriate for gestational age infants, which also suggests that the bore of the mesenteric vessels of small for gestational age infants is narrower than normal.

If we assume that the differences in velocity that we found are associated with similar differences in volume of flow, we could infer that severely growth retarded infants have lower gut blood flow on the first day of life than infants who are appropriate for gestational age. Infants with fetal hypoxia (indicated by absent end diastolic frequencies) are the most severely affected. The differences between the groups cannot be explained by differences in blood pressure, oxygenation, or enteral feeding (table 2); they probably represent a specific defect of visceral perfusion rather than a general perfusion defect, as the velocity in the anterior cerebral artery was similar in all the groups studied. The magnitude of the differences was such that infants with absent fetal end diastolic frequencies had mesenteric artery velocities nearly $40 \%$ lower than their controls. Because it has been shown in animals that intestinal oxygen consumption falls when blood flow is decreased by more than $30 \%,{ }^{4}$ and that ischaemic tissue injury occurs after a $50 \%$ reduction, ${ }^{5}$ the observed changes could have clinically important effects.

The pulsatility index was significantly higher in the superior mesenteric artery and coeliac axis of infants with absent end diastolic frequencies than in either group of controls. This suggests that the infants who were small for gestational age had either a greater amount of left to right ductal shunting ${ }^{6}$ or an increased impedance to visceral blood flow. We did not attempt to use ultrasound to document the size or incidence of ductal shunting at the time of measurement, but the later incidence of clinical patent ductus arteriosus was lower among small for gestational age infants (4/18) than among weight matched $(8 / 18)$ or gestation matched $(6 / 18)$ controls. Increased intestinal vascular resistance is probably the best explanation of our findings.

The higher velocity in the anterior cerebral artery on day 3 in infants who were small for 
gestational age may resemble the postanoxic 'luxury' hyperperfusion that is seen in hypoxicischaemic encephalopathy. ${ }^{7}$

Mean superior mesenteric artery velocity on the seventh day of life was significantly lower in small for gestational age infants than in gestation matched controls, although similar numbers were receiving enteral feeds. Superior mesenteric artery velocity was much closer to that of the weight matched controls, few of whom were enterally fed. As well as the absolute values being lower, the percentage increase over day 1 values was also reduced: One explanation is that the vascular response to enteral feeding that is seen in normal infants is deficient in severely growth retarded infants, ${ }^{89}$ but this warrants further prospective study. A lack of vascular response has been shown in animals that are hypoxic at the time of feeding. ${ }^{10}$

Fetuses that are small for gestational age and have absent end diastolic frequencies in the fetal aorta are at increased risk of developing necrotising enterocolitis. ${ }^{3}$ Our results suggest that the abnormal patterns of perfusion that have previously been shown in fetuses persist into postnatal life, and could result in further hypoxic-ischaemic tissue damage or maturational delay in addition to that which may have occurred in utero. It is possible that the low baseline intestinal blood flow velocity, which does not increase after enteral feeding, would be unable to meet the additional metabolic demand that such feeding imposes on the gut. We suggest that caution should be exercised when introducing enteral feeds to VLBW infants with severe IUGR, especially to those in whom fetal hypoxia was suspected antenatally.

1 Nicolaides KH, Economides DL, Soothill, PW. Blood gases, $\mathrm{pH}$ and lactate in appropriate and small for gestational age fetuses. Am ₹ Obstet Gynecol 1989;161:996-1001.

2 Billardo CM, Nicolaides KH, Campbell S. Doppler measurements of fetal and uteroplacental circulations: relationship with umbilical venous blood gases measured at cordocentesis. Am f Obstet Gynecol 1990;162:115-20.

3 Hackett GA, Campbell S, Gamsu H, Cohen-Overbeck T, Pearce JMF. Doppler studies in the growth retarded fetus and prediction of neonatal necrotising enterocolitis, haeand prediction of neonatal necrotising enterocolitis, hae-

morrhage, and neonatal morbidity. BMF 1987;294:13-6. vietys PR, Granger DN. Relation between intestinal blood flow and oxygen uptake. Am F Physiol 1982;242:G202-8.

5 Bulkley GB, Kvietys PR, Parks DA, Perry MA, Granger DN. Relationship of blood flow and oxygen consumption to ischemic injury in the canine small intestine. Gastroenterology

6 1985;89:852-7.

Coombs RC, Morgan MEI, Durbin GM, Booth IW, McNeish AS. Gut blood flow velocities in the newborn: effects of patent ductus arteriosus and parenteral indomethacin. Arch Dis Child 1990;65:1067-71.

7 Archer LNJ, Levene MI, Evans DM. Cerebral artery doppler ultrasonography for prediction of outcome after perinatal asphyxia. Lancet 1986;ii:1116-8.

8 Leidig E. Doppler analysis of superior mesenteric artery blood flow in preterm infants. Arch Dis Child 1989;64:476-80.

9 Gladman G, Sims DG, Chiswick ML. Gastrointestinal blood flow velocity after the first feed. Arch Dis Child 1991;66: $17-20$.

10 Szabo JS, Mayfield SR, Oh W, Stonestreet BS. Postprandial gastrointenstinal blood flow and oxygen consumption: 21:93-8. 